\title{
S3 Guideline “Management of Patients with Non-Specific, Functional and Somatoform Physical Complaints" - What is Important for Gynaecological Practice?
}

\author{
S3-Leitlinie „Umgang mit Patienten mit nicht-spezifischen, funktionellen und somatoformen \\ Körperbeschwerden“ - Was ist bedeutend für die gynäkologische Praxis?
}

Authors

Affiliations

\section{F. Siedentopf ${ }^{1}$, C. Hausteiner-Wiehle ${ }^{2}$}

${ }^{1}$ Martin-Luther-Krankenhaus, Frauenklinik, Berlin

2 Berufsgenossenschaftliche Klinik Murnau, Klinik und Poliklinik für Psychosomatische Medizin der Technischen Universität, München

\section{Key words}

- gynaecology

- somatoform physical complaints

- primary psychosomatic care

- chronic pelvic pain in women

Schlüsselwörter

- Gynäkologie

- somatoforme Körperbeschwerden

- psychosomatische Grundversorgung

- chronischer Unterbauchschmerz der Frau

\section{Bibliography}

Dol http://dx.doi.org/

10.1055/s-0032-1328381

Geburtsh Frauenheilk 2013; 73:

224-226 ๔ Georg Thieme

Verlag KG Stuttgart - New York . ISSN 0016-5751

\section{Correspondence}

Dr. med. Friederike Siedentopf

Martin-Luther-Krankenhaus, Frauenklinik

Caspar-Theyß-Straße 27-31

14193 Berlin

friederike.siedentopf@gmx.de

\section{Abstract \\ $\nabla$}

When the guideline was compiled, the available evidence was heterogeneous; the evidence varied depending on the subject addressed and was often of only moderate quality. Nevertheless, a strong consensus was reached on almost all subjects. It is recommended that physicians develop a collaborative working relationship with the patient, focus on symptoms and coping strategies and avoid making stigmatising comments. A biopsychosocial diagnostic evaluation with a sensitive discussion of the signs of psychosocial stress allows problems of this type and co-morbid conditions to be recognised early on and reduces the risk of iatrogenic somatisation. In uncomplicated cases, establishing a biopsychosocial explanatory model and physical/social activation are recommended. More serious cases call for collaborative, coordinated management with regular appointments (as opposed to ad-hoc appointments when the patient feels worse), gradual activation and psychotherapy. The comprehensive treatment plan can be multimodal and can potentially include physical management strategies, relaxation techniques and antidepressants.

\section{Zusammenfassung \\ $\nabla$}

Bei der Erstellung der Leitlinie war die Evidenzlage heterogen und erreichte bei vielen Fragen nur mittleren Evidenzlevel; starker Konsens wurde jedoch fast durchgehend erzielt. Empfohlen werden der Aufbau einer partnerschaftlichen Arbeitsbeziehung, eine symptom-/bewältigungsorientierte Grundhaltung und das Vermeiden stigmatisierender Kommentare. Biopsychosoziale Simultandiagnostik mit behutsamem Aufgreifen von Hinweisen auf psychosoziale Belastungen ermöglicht die Früherkennung einschließlich komorbider Erkrankungen und verringert das Risiko iatrogener Somatisierung. Bei leichteren Verläufen helfen das Erarbeiten eines biopsychosozialen Erklärungsmodells und körperliche/soziale Aktivierung. Schwerere Verläufe erfordern ein kooperatives, koordiniertes Vorgehen mit regelmäßigen Terminen, gestufter Aktivierung und Psychotherapie. Innerhalb eines Gesamtbehandlungsplans bis hin zu multimodaler Therapie können körperorientierte und Entspannungsverfahren sowie antidepressive Medikation sinnvoll sein.

\section{Introduction}

\section{$\nabla$}

The guideline on non-specific, functional and somatoform physical complaints provides practical interdisciplinary recommendations; the aim is to improve the understanding of biopsychosocial disease and facilitate early recognition, prevention and therapy.

When the guideline was compiled, the available body of evidence was quite heterogeneous due to the breadth of the topic; moreover, the level of evidence for many of the topics addressed was only moderate. Nevertheless, a strong consensus was reached among the 30 involved professional associations and patient representative bodies [1-3].

Principal symptoms include pain at different localisations, disturbance of organ function (digestion, cardiovascular system, breathing, urogenital system) and can include vegetative symptoms such as exhaustion/fatigue [4]; basically, symptoms can occur in every organ. Many somatic disciplines have therefore formulated their own functional syndromes; in gynaecology these include chronic pelvic pain, vulvodynia, chronic vaginal pruritus/chronic vaginal discharge, dysmenorrhea and dyspareunia. 
Recent etiopathogenetic models take the complex interactions between psychosocial, biological, iatrogenic/medical and sociocultural factors as their starting point. These interactions can lead to neurobiological changes due to a combination of the patient's disposition and the triggers, and can result in a chronification of symptoms [1-5].

\section{Approach and counselling: focus on empathy, biopsychosocial factors and coping strategies \\ $\nabla$}

The basic approach should aim for an empathetic understanding of symptoms in the context of the patient's situation. It should take account of somatic and psychosocial aspects with the aim of improving the patient's quality of life and performance (rather than insisting on explanations and remedies for symptoms) [13]. Therapists should offer a positive description of symptoms (for example, "non-specific", "functional”, "physical stress", or another suitable diagnosis) and should avoid comments which play down the condition ("There is nothing wrong with you") or stigmatising descriptions ("hysteria") $[1-3,6,7]$. Reassurance is important: patients should be reassured that symptoms are unlikely to progress to serious disease and that no unsuitable measures will be taken ("nil nocere") $[1-3,8,9]$. Therapists should use open questions which allow the patient to choose the aspect she wishes to describe first herself; such questions promote the flow of discussion, encourage the patient to cooperate with the therapist and signal that the therapist wishes to work together with the patient. Attentiveness and interest should be indicated through verbal and nonverbal signs ("active listening") [1-3].

\section{Diagnostics: favourable prognostic factors, characteristics of more severe courses}

A biopsychosocial diagnostic approach is recommended which focuses on the psychosocial context and simultaneously excludes important somatic differential diagnoses [1-3]. When taking the patient's history it is important to discover whether other physical and psychological complaints are present in addition to the main presenting symptoms. Triggers, coping strategies and the current level at which the patient can function in daily life need to be investigated. The somatic diagnosis needs careful planning and should not be redundant; it should include regular physical examinations but avoid unnecessary and potentially injurious measures. Examinations and examination results should be discussed in a way that will discourage any tendency to focus on catastrophic outcomes.

Certain protective factors ("green flags") are likely to have a positive prognostic impact and should be noted and encouraged ( Table 1). Characteristics indicative of a more serious course ("yellow flags") ( Table 2), and warning signals including suicidal tendencies which indicate a potentially dangerous course ("red flags") ( Table 3) should be repeatedly assessed, and treatment needs to be adapted accordingly [4].

The diagnosis may also include co-morbid disorders such as functional or somatoform disorders.
Table 1 Protective factors (“green flags") (based on [1-4, 10,11]).

Active coping strategies (e.g. physical exercise, positive approach to life, motivated for psychotherapy)

Healthy lifestyle (enough sleep, well-balanced diet, exercise and relaxation) Secure attachments, social support

Good working conditions

Successful relationship between therapist and patient

Biopsychosocial approach which avoids unnecessary measures and discourages any tendency to focus on catastrophic outcomes

Access to healthcare which focuses on personal responsibility and prevention

Table 2 Clinical characteristics of a more serious course ("yellow flags") (based on $[1-4,10,11]$ ).

Several symptoms (poly-symptomatic course)

No or only rare/short periods without symptoms

Severe fear of disease

Highly dysfunctional utilization of healthcare services, defensive avoidance strategies

Incapacity to work $>4$ weeks, social withdrawal

High levels of stress in current situation and in prior history

Severe psychological co-morbidities (depression, anxiety, PTSD, addiction, personality disorder)

Patient-physician relationship experienced as "difficult" (by both parties), frustrating, treatment frequently discontinued

latrogenic somatisation (e.g. focus on catastrophic outcomes, invasive procedures which are not indicated)

Table 3 Warning signals for a preventable severe course ("red flags") (based on $[1-4,10,11])$.

Suicidal tendencies
Serious psychological co-morbidities (e.g. severe depressive episode(s),
anxiety symptoms which prevent the patient from leaving the house)
Indications of serious self-harming behaviour (insisting on surgery)
and/or iatrogenic intervention
Very severe symptoms resulting in physical damage: fixated on unhelpful/
harmful behaviour, strong weight gain, limited mobility
Presence of well-known warning signals for somatically defined disease
(cf. guidelines for somatic disciplines)

\section{General Therapeutic Recommendations \\ $\nabla$}

Therapy will depend on the severity of symptoms and the clinical characteristics $[4,12,13]$. For most female patients with non-specific, functional and somatoform physical complaints, their first port of call will be their general practitioner [14,15], but if symptoms have a gynaecological aspect women are likely to turn first to their gynaecologist ("the woman's GP"). If psychological and somatic co-morbidities are present, these co-morbid conditions require appropriate treatment in accordance with the guidelines. For less serious conditions, establishing a biopsychosocial explanatory model and physical/social activation are recommended. Symptoms and findings should be explained descriptively and rechecked with the patient, and the connection between psychology and physiology needs to be communicated to the patient (psychoeducation: e.g. stress physiology, vicious circle model). It is useful to begin by building on the patient's subjective theory about her illness and use it to develop a biopsychosocial explanatory model [1]. 
Serious cases require longer term monitoring and cooperative, coordinated management with regular appointments (which should take place whether the patient is symptomatic or not), staged physical and social activation, and psychotherapy (using a wide range of data and a moderate effect size for cognitive-behavioural, psychodynamic-interpersonal or hypnotherapeutic/ imaginative therapy). The comprehensive treatment plan can be multimodal, and include body-oriented/non-verbal and relaxation techniques (ideally, activating techniques which can also be done at home) as well as pharmacotherapy for a limited period of time; if the predominant symptom is pain, treatment with antidepressants may be helpful.

The therapy offered by the somatic physician or gynaecologist should consist of "psychosomatic basic care" and - if the physician/gynaecologist is qualified to do so - targeted psychotherapy [1].

- Table 4 lists typical indications for inpatient treatment based on the clinical course (decisions must be made on a case-by-case clinical basis!).

\section{Conclusion \\ $\nabla$}

In conclusion, simultaneous biopsychosocial diagnostics can help recognise problems of this type early on and prevent additional "iatrogenic somatisation" using collaborative interpersonal communication and careful diagnostic planning. Treatment depends on the severity of disease and should be coordinated by the patient's gynaecologist ("woman's GP"). It requires the active participation of the patient and the cooperation of all attendant healthcare professionals.

In addition to background comments and sources, the long version of the guideline includes practical advice and numerous suggestions on phrases to use. Both the long and short versions of the accompanying patient guideline focus on information and suitable self-help measures: www.awmf.org/leitlinien/detail/l1/ 051-001.html

\section{Table 4 Typical indications for inpatient treatment $[2,3]$.}

Posing a threat to oneself or to others, including suicidal tendencies (absolute
indication), need to have medical help constantly on hand to deal with poten-
tial crises
Severe physical symptoms and/or severe somatic co-morbidities, severe
psychological symptoms and/or marked psychological co-morbidities
Unable to work for a longer period of time (at least 4 weeks) which may put the
patient's ability to earn a living at risk, limited social support, serious familial or
workplace-related conflicts, other relevant socio-medical aspects
Insufficient motivation to undergo treatment or lack of resilience with regard
to pursuing outpatient therapy, purely somatic understanding of illness
Serious stresses in the patient's prior history
Serious interaction difficulties between healthcare staff and patient
No success reported for outpatient treatment after 6 months ([temporary]
inpatient therapy should be considered if an evaluation of the patient's prog-
ress, which should be done every 3 months, twice shows that outpatient
treatment has not been successful)
Problems of logistics or availability when attempting to make a multimodal
(differential) diagnosis and offer treatment by a range of different healthcare
professionals
Treatment plan must be change or adapted and progress must be monitored
by a team composed of different professionals supervised by a physician,
onward treatment necessary to change the external framework
Patient's own request

\section{Acknowledgement}

We would like to thank the other authors (Rainer Schaefert, Winfried Häuser, Joram Ronel, Markus Herrmann and Peter Henningsen) of the condensed version of the guideline, published in November 2012 in the Deutsches Ärzteblatt [1], on which this article is based, and also to thank all persons who contributed to developing the long version of the guideline.

\section{Conflict of Interest \\ $\nabla$}

C. Hausteiner-Wiehle: None.

F. Siedentopf has received speaker's fees from the companies Roche, GlaxoSmithKline and Dr. Kade-Besins.

\section{References}

1 Schaefert R, Hausteiner-Wiehle C, Häuser $W$ et al. Clinical Practice Guideline: Non-specific, functional and somatoform bodily complaints. Dtsch Arztebl Int 2012; 109: 803-813

2 Hausteiner-Wiehle C, Schaefert R, Sattel Het al. AWMF-Leitlinie zum Umgang mit Patienten mit nicht-spezifischen, funktionellen und somatoformen Körperbeschwerden. AWMF-Reg.-Nr.051-001 2012. www. awmf.org/leitlinien/detail/1l/051-001.html; Stand: 25.2.2013

3 Hausteiner-Wiehle C, Henningsen P, Häuser Wet al. Umgang mit Patienten mit nicht-spezifischen, funktionellen und somatoformen Körperbeschwerden. S3-Leitlinien mit Quellentexten und Praxismaterialien. Stuttgart: Schattauer; 2013: in press

4 Henningsen P, Zipfel S, Herzog W. Management of functional somatic syndromes. Lancet 2007; 369: 946-955

5 Witthöft M, Hiller W. Psychological approaches to origins and treatments of somatoform disorders. Annu Rev Clin Psychol 2010; 6: 257283

6 Dowrick CF, Ring A, Humphris GM et al. Normalisation of unexplained symptoms by general practitioners: a functional typology. Br J Gen Pract 2004; 54: 165-170

7 Stone J, Wojcik W, Durrance D et al. What should we say to patients with symptoms unexplained by disease? The "number needed to offend". BMJ 2002; 325: 1449-1450

8 Fink P, Rosendal M, Toft T. Assessment and treatment of functional disorders in general practice: the extended reattribution and management model - an advanced educational program for nonpsychiatric doctors. Psychosomatics 2002; 43: 93-131

9 van Bokhoven MA, Koch $H$, van der Weijden T et al. Influence of watchful waiting on satisfaction and anxiety among patients seeking care for unexplained complaints. Ann Fam Med 2009; 7: 112-120

10 Kirmayer LJ, Robbins JM. Three forms of somatization in primary care: prevalence, co-occurrence, and sociodemographic characteristics. J Nerv Ment Dis 1991; 179: 647-655

11 Smith RC, Dwamena FC. Classification and diagnosis of patients with medically unexplained symptoms. J Gen Intern Med 2007; 22: 685691

12 van der Feltz-Cornelis CM, Hoedeman R, Keuter EJ et al. Presentation of the Multidisciplinary Guideline Medically Unexplained Physical Symptoms (MUPS) and Somatoform Disorder in the Netherlands: disease management according to risk profiles. J Psychosom Res 2012; 72: 168-169

13 Gask L, Dowrick C, Salmon P et al. Reattribution reconsidered: narrative review and reflections on an educational intervention for medically unexplained symptoms in primary care settings. J Psychosom Res 2011; 71: 325-334

14 Steinbrecher $N$, Koerber S, Frieser $D$ et al. The prevalence of medically unexplained symptoms in primary care. Psychosomatics 2011; 52: 263-271

15 Nanke A, Rief $W$. Zur Inanspruchnahme medizinischer Leistungen bei Patienten mit somatoformen Störungen. Psychotherapeut 2003; 48: 329-335

Deutschsprachige Zusatzinformationen online abrufbar unter: www.thieme-connect.de/ejournals/toc/gebfra. 